\title{
CONCLUSION: \\ THE FRENCH JESUIT MISSION REVISITED
}

The aim of this study has been to seek a fresh interpretation of the Jesuit mission to New France in the light of the earlier Iberian experience in Japan. The existing historical paradigms of the French Jesuit mission to the Amerindians have been examined from a broader global standpoint well beyond North America. The time period encompasses one entire century, from the mid-sixteenth to the mid-seventeenth century. The worldwide Jesuit mission has been analysed as a series of incidents that unfolded internationally, beginning with the early mission by Father Francisco de Xavier in Japan, long before the establishment of the seventeenth-century French mission. The Christian mission in Japan provides a useful approach for revising the currently accepted historical interpretations of events in New France.

Under this new paradigm, this study has set forth several keys that lead to a cautious revisionist interpretation of the religious history of the French colony of North America. First, the missionaries began their activity by drawing on the experience of their predecessors in Japan. Second, there are certain patterns in the biases in the missionary accounts. Thus, the biases can be identified, and can be used to analyse the missions when reading the documents. Third, there was methodological continuity, rather than institutional differences, between the Franciscans and the Jesuits in their missionary policies. Fourth, in the multifaceted strategies that the missionaries developed internationally, the Jesuit approach should not be described as a single line that ran from evangelising children to converting adults. Fifth, the Amerindian réductions were not simply based on the reducciónes in Paraguay. One can find a prototype for the réductions both directly and indirectly in the Japanese Christian communities. Sixth, the Amerindian notion and practice of Christianity was beyond the priests' accounts of exemplary Christians, and thus should be discussed in terms of cultural interaction rather than in terms of religious or colonial conquest. Because of these keys, a case has been established for the revision of these aspects of the historiography of New France.

The Introduction, to begin with, has explained why an international perspective is necessary to understand the mission in New France. There was a connection between the missions in Japan and in those New 
France. There was a global web of missionary correspondence centred in Europe. In France and other countries, the reports from Japan were translated and published in numerous languages such as French, Latin and Italian, all of which the French missionaries were able to read. ${ }^{1}$ This is why the Jesuit reporters in the Jesuit narrators were familiar with the Iberian mission in Japan.

The review of literature on the Jesuit missions in the first chapter has shown the necessity for including the Iberian missions of the sixteenth century in any study of the Jesuits in the Americas. In the historiographies of both New France and Japan, there have been numerous contributions to the understanding of the Christian missions. Granted, each area of study developed independently of the other, but the French priests were never ignorant of Father Xavier and other Iberian predecessors. Father Xavier was a saint and a model for them.

Through the classification of missionary approaches, the next three chapters, two to four, have revealed epistemological problems in the historical understanding of the French Jesuit mission. These problems lie in the inherent biases of the Jesuit documents, in the evolution of multifaceted evangelistic strategies and in the creation of native Christian communities. In these three aspects, this study has found room for revisionist proposals.

The second chapter has identified the biases that ruled the missionary accounts. The clue to this identification has been analysing how the frequently repeated themes appeared in the missionary correspondence. These biases cannot be clearly identified solely through the speculative reading of the Jesuit accounts about New France. To overcome this limitation, the contrast between the written interpretations by the Iberian Jesuits of Japanese culture and actual Japanese culture has been used as a tool for identification of their biases. The biases that ruled the cross-cultural understanding of Japan were not peculiar to the Iberian Jesuits. The French missionaries failed to recognise that they might be making an equally mistaken analysis that their Iberian predecessors had made in their reports.

This study has recognised two basic characteristics of missionary biases. The first characteristic is that there were two types. One was

\footnotetext{
${ }^{1}$ One should realise that not all of the Jesuits in New France were French. Father Francis Joseph Bressani, for example, was an Italian who served for the French mission.
} 
thematic bias while the other was interpretive. The identification of these two biases has shed light on the French priests' observations of indigenous North American cultures. The second characteristic is that the interests of the Jesuit order, rather than the priests' own personal initiatives, dominated the thematic and interpretive descriptions of a non-Christian culture. The changing situations at each developmental stage of evangelistic activity generally determined the Jesuit interpretations of a non-Christian culture.

This substantial identification of European biases has exposed the interconnection between the biased cultural observations by the Iberian priests and those by the French priests. What is to be noted is that Euro-Christian readers of the missionary accounts were unable to recognise the Iberian misunderstandings of Japan and its people, since the written accounts were strictly determined by Euro-Christian biases. In the rhetoric of the missionary reports, the French reporters made epistemological mistakes similar to those made by their Iberian predecessors.

Furthermore, the analysis of the Iberian experience in Japan from a Japanese perspective has helped to confirm that the French missionaries depended on their own cultural framework to understand Amerindian customs. Fully convinced that the native beliefs were superstitions rather than a religion, they nevertheless resorted to Euro-Christian religious concepts for their interpretation of these indigenous beliefs. When the Jesuits could not understand any particular Amerindian spiritual custom, they were forced to explain it by resorting to their own version of diabolism.

The second chapter has also proposed another rhetorical limitation in these evangelistic reports. The reporters had to adjust their written expressions to suit the European readers' limited cultural and linguistic understanding. In other words, when they wrote about their experiences abroad, they had to decide what to mention and how to describe it. They interpreted their experiences much better in their own minds than in their written accounts, which of course were designed to be understood by French readers in Europe.

The identification of biases and rhetorical restrictions has revealed the pattern of the French Jesuit observations. The Jesuits described the visible aspects of native culture in their own pragmatic way. In their interpretations of non-Christian peoples, they are more restricted and distorted not only by wilful descriptive manipulation but also by the limitations of cultural differences. Their written accounts present the 
image that the missionaries expected their readers to hold about native people and their culture. Among other things, The Jesuit Relations served as tools to justify their choice of potential converts.

It is this political pragmatism that explains why the Jesuit accounts of New France are full of negotiations with influential native leaders. It was this pragmatism that drove the Jesuits to search for those with power and authority. These political elements were important to help them to figure out whom to approach first as a potential patron. Their analysis of the Amerindian social structure was directed towards the same strategic ends of locating the centres of power to be used for their own purposes.

The third chapter has explored the evolution of multifaceted strategies in order to look for a better interpretation of two established schools of thought about the New France mission. This chapter began by considering how Father Xavier devised an approach to the Japanese in the mid-sixteenth century. The chapter also illustrated how the Jesuit successors developed his evangelistic methods from that time until the mid-seventeenth century. Thus, the Jesuits in New France did not have to develop their own evangelistic approach from scratch. Instead, they built upon what they read in reports from Japan, and they could thereby improve their strategies for preaching and winning converts as well as for educating the native peoples.

Interpreting how the missionary strategies evolved over time has proposed more appropriate interpretations for two important issues. The first issue is that, in Canadian historiography, the Franciscan missionaries have been labelled cultural absolutists, and, on the other hand, the Jesuit missionaries are called cultural relativists. In Japan, however, the Franciscan policy was no different from the Jesuit policy, as far as the introduction of Euro-Christian culture is concerned. The strategies of these two religious orders in Japan have yielded another possibility for interpretation. When this flow of information from Japan to New France via Europe is taken into account, it is clear that one should adjust simplistic labels like cultural absolutism and cultural relativism, which have formed part of the Canadian interpretation.

Most methodological differences in the mission of New France were not caused by the institutional difference between the two religious orders. The difference was to be found elsewhere, between the pioneer missionaries and those who came later to the Saint Lawrence Valley and Great Lakes regions. Any detectable difference was the result of continual evolution of evangelistic strategies throughout the first half of the 
seventeenth century. The priests adjusted their missionary methods in accordance to the ever-changing cultural environment around them. This adjustment caused the evolution of missionary policies over time.

The second issue is whether the missionaries gave priority to adults or the young using one single method to convert the Amerindians, as has been claimed repeatedly in the Canadian historiography. Methodological similarities between the Iberian and French missions have demonstrated that the Jesuits, since the earliest years in Japan, had already evolved multifaceted strategies internationally when the French Jesuits began their work in North America. Converting the general adult population and educating children were two independent activities, and each had its own motive. The former was essential for creating a Christian community, while the latter was fundamentally based on the educational mandate of the Jesuit order. The Jesuit approach was not a shift from converting children to evangelising adults.

A more nuanced interpretation for this issue of conversion and education is that the Jesuit missionaries worked with a variety of approaches, with an emphasis on two basic lines. One was political diplomacy, and the other was philanthropy. The missionaries were diplomatically careful about whom to approach for their best evangelistic foundation. Philanthropy served as a tool for attracting a wide range of the population. Missionary education may be a third independent line of approach if it is regarded as part of the Jesuit principle of missionary activity. One should distinguish these plural lines of methodological evolution in the missions in order to understand the international evolution of the multifaceted methods beyond New France.

Next, in a global perspective beyond New France, the fourth chapter has reconsidered the popular idea that colonial French réductions were modelled on the Paraguayan reducciónes. The first step in this reconsideration has been to confirm that there was no definitive explanation of the origin of the Paraguayan scheme for creating Christian communities. The second step has been to find references to Japan as the goal of the mission in the Jesuit documents on Paraguay, as well as finding the Japanese legacies in the names of reducciónes. In a third step, based on these first two steps, methodological interconnection has been established between Japanese Christian villages in Hizen and the Paraguayan Christian communities. In a final step, a similar interconnection between the réductions and the reducciónes has been examined. These four stages of analysis have proposed the need to revise repeatedly-stated opinions about Amerindian Christian communities. 
From several examples of comparisons, it is true that the Laurentian réductions emulated aspects of the Paraguayan reducciónes. The Jesuits established some degree of political autonomy in the réductions. They were at least partly successful in settling the Innu and Algonquin peoples in réductions. The missionaries gained control of native community administration. They shared the same policies with their predecessors in Paraguay both in their philanthropic spirit for invalids and in their indifference to the prevention of epidemics. Nevertheless, all these approaches have turned out to have been emulations of the Iberian mission in Japan.

The fourth chapter has also shown that the réductions resembled more closely the Japanese Christian communities in several other ways. The segregation of réductions was just as incomplete as that of the Christian villages in Hizen. The missionaries both in Japan and in New France tolerated traditional clothing and made little effort to replace it with European-style garments. Both missionary groups were tolerant of indigenous dwellings for converts. More significantly the French Jesuits revived the office of dogiques from the Iberian experiments of Japanese dôjuku, a term never used in Paraguay.

Thus, the widely-held scholarly opinion concerning the prototypes for the réductions needs to be reconsidered with regard to the following two aspects. One is that the Jesuits in Paraguay did not create the idea for the reducciónes without precedent. These reducciónes were instead based on models of the Jesuit experiments in Asia, especially in Japan. Likewise, the prototype for réductions in New France has been discovered beyond Paraguay. Another aspect is that the réductions did not completely emulate the Paraguayan models. This study has shown that the design of colonial French réductions originated not only in a Paraguayan model but also directly in the Japanese Christian communities.

This international connection has turned out to be more complex. It is to the creation of Japanese Christian villages that most of the fundamental characteristics of the Laurentian réduction scheme can be traced, either directly or indirectly. The distinctive features of those réduction approaches that were obviously alien to the Paraguayan experiment, were not original to the French Jesuits. Rather, they are much more likely to have been the approaches emulated and developed directly from the successful endeavours to establish Christian villages in Japan. 
Based on the above consideration of evangelistic methods, the fifth chapter has altered the angle of perspective from one-sided missionary attempts to an interaction between priests and indigenous people. The discussion in this chapter begins by pointing to the epistemological limits of existing general approaches to the non-European practice of Christianity. The conventional focus on the degree of conversion to authentic Christianity prevented the recognition of the priests' major concerns about conversion as well as the identification of typical Christians. Nor did the conventional focus grasp the collective, rather than individual, acceptance and comprehension of the faith.

Based on this premise, the fifth chapter has discussed the Japanese response to missionary attempts, in order to identify the process by which non-European converts became Christians. In so doing, the meaning of the Jesuit evangelisation has been reconsidered in the context of non-European culture. Also, the major determinants in formulating the Japanese practice of Christianity have been sought out. Above all, the argument has revealed the nonconformity between European and non-European ideas concerning the true meaning of conversion to Christianity.

This comparative approach has been applied in order to reinvigorate and revise the existing historiographical debate on the Amerindian practice of Christianity. Up until now, the debate has been ruled by the rhetorical universe of The Jesuit Relations, and has been expressed in terms of conquest and subordination. As well, the debate was shaped by the degree of evangelical success. To revise these perspectives, this study has attempted to draw a more plausible picture of Amerindian acceptance and comprehension of the Europeans' religion.

This study makes it clear that Christianity meant several things to Amerindian converts. Christianity, with its divine grace, was the key to access to worldly benefits and social services. Christianity also replaced the traditional hereditary tie to indigenous society with a new tie only available through Christian prayers and sacraments. It worked as a social tie creating new communities in the réductions. The Christian religion was believed to provide a supernatural healing and killing power that Amerindians expected on the basis of their own non-Christian beliefs.

This study has identified one dominant factor that helps to explain the meaning of conversion. The Jesuit approach was adjusted to suit Amerindians and was the primary determinant for the acceptance and comprehension of Christianity. Non-Christian cultural compatibility 
with the new religion was only of secondary importance. The priests were adept at modifying their methods based on their understanding of the social and spiritual environment of the indigenous people. The Jesuits borrowed from Amerindian customs whatever was equivalent to Christian elements.

This Amerindian version of the faith was a result of native responses to the Jesuit mission. The indigenous people understood the tactful Jesuit preaching within the traditional framework of custom. Through the limited indigenous resources based on this emulation and on their selective emphasis on specific aspects of missionary services, the Amerindian people developed their own concepts of Christianity. In so doing, their version of Christianity proved to be beyond the scope of the rhetorical references to model proselytes in The Jesuit Relations.

Therefore, the history of Christian missions in seventeenth-century New France and the cross-cultural relations incidental to them need to be revised. The Jesuit mission in New France is not only a part of North American history but also a part of global history. This study has demonstrated that placing events of New France within an international perspective enables one to understand more accurately why and how the Jesuit missions adopted particular policies in the development of their evangelistic programme.

This thesis has also pointed out that Amerindian Christianity can be fully discussed neither in terms of evangelistic success nor in terms of cultural transformation. Christian conversion was a complex process of interaction between two cultural groups. One side included those who attempted to propagate the religion extensively and effectively. The other included those who tried to accept and integrate it into a non-Christian culture in a comprehensible manner.

This diachronic comparison of the missions may be just one example of possible perspectives for better recognition of a past that may have something to tell us today about cultural transfer. The comparison is also an important key to improved understanding of the missionary experience in New France. Furthermore, in this new historical perspective on New France, there is much room for further development. 